\title{
Predatory feeding behavior of an Antarctic marine copepod, Euchaeta antarctica
}

\section{JEANNETTE YEN}

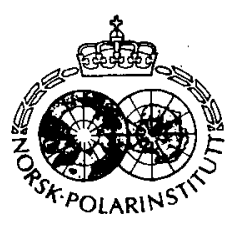

Yen. J. 1991: Predatory feeding behavior of an Antarctic marine copepod, Euchaeta antarctica. Pp. 433-442 in Sakshaug, E., Hopkins, C. C. E. \& Øritsland, N. A. (eds.): Proceedings of the Pro Mare Symposium on Polar Marine Ecology, Trondheim, 12-16 May 1990. Polar Research 10(2).

During the austral summer, fall and winter, feeding rates of Euchaeta antarctica were measured in the laboratory. Measurements were taken over 24 hours in the dark on a mixing device at the ambient temperature using lively prey and predators in good condition with intact first antennae. Under these conditions, I found that no feeding occurred during winter so the following characterizes summertime feeding behavior. Adult females of Euchaeta antarctica are exclusive carnivores, exhibiting highest feeding rates on prey having a prosome length of $1200 \mu \mathrm{m}$. The size of these preferred prey was $65 \%$ the length of the second basipodal segment of the maxilliped, the main appendage used in prey capture by $E$. antarctica. These prey, juvenile stages of Metridia gerlachei, also were the most abundant prey available in the plankton. The mean saturation ingestion rate of the adult female on their preferred prey of 18.7 Metridia/female/d is $8.8 \%$ its body weight, of which $17.3 \%$ is respired. A three-week starvation period caused less than a 1.5 fold increase in the feeding rate. Maximum volume effectively searched by this predatory copepod was 2.4 liters/day. Fecal pellets were produced at a constant rate of 0.697 pellets/hour; this rate was not infuenced by the level of gut fullness. In order to produce one fecal pellet, E. antarctica must ingest 1.63 prey of the preferred size. Assuming that the rate of egestion is equal to the rate of ingestion, prey were ingested at a rate of $1.14 / \mathrm{h}$. Many of the field-caught copepods evacuated 3-5 pellets which converts to 5-8 copepod prey ingested. This in situ meal more than adequately covers their daily respiratory costs.

Smaller predators, CIV and CV E. antarctica, exhibited higher rates on smaller prey while males did not feed at all. The younger and potentially faster growing stage CIV consumed a higher proportion of their body weight per day than did the older mature predators; they were able to meet their metabolic costs on large and small prey. Older stages may not be able to obtain enough food to meet their metabolic needs during the late summer when prcy availability is limited; they cease feeding and go into the overwintering state.

Jeannette Yen, Marine Sciences Research Center, State University of New York, Stony Brook. New York 11794-5000, USA.

\section{Introduction}

Euchaeta antarctica is one of three copepod species (Calanoides acutus, Metridia gerlachei) that dominate the zooplankton biomass of the copepod community of Croker Passage, a deep water connection between the Bransfield and Gerlache Straits off the Antarctic peninsula (Hopkins 1985b). E. antarctica's rank as a biomass dominant may be attributed to its large size (10 $\mathrm{mm}$ total length, $6 \mathrm{mg}$ dry weight) and large reserve of lipids, comprising up to $46 \%$ of its dry weight (Littlepage 1964). E. antarctica is among the most common euchaetid species throughout Antarctic waters, occurring abundantly in intermediate and deep layers (Bradford et al. 1983; Park 1978). In the deep $1200 \mathrm{~m}$ basin of Croker Passage, the species resides between 1000 and
$200 \mathrm{~m}$, with the bulk of the population remaining below $600 \mathrm{~m}$ (Hopkins 1985b; Yen pers. obsn.).

$E$. antarctica is also an important member of the Antarctic food web, both as food for higher planktivores and as a carnivorous copepod that feeds predaceously on other copepods. $E$. antarctica is the principal diet item for some chaetognaths, amphipods, midwater fish (Hopkins 1985a), and brittle stars (Dearborn et al. 1986). Within the guts of Euchaetidae, the most frequently occurring prey were the small copepods: Oncaea spp. and copepodites of $M$. gerlachei (Hopkins 1985a).

In this study, I further examined the diet composition and predatory feeding ecology of $E$. antarctica. I demonstrated size-selective feeding behavior of the adult female stage of $E$. antarctica in laboratory experiments. Morphometric analy- 
ses showed a relationship between prey size and size of the predatory feeding appendage. Offering the preferred prey, I measured saturation ingestion rates of fed and starved predators, their clearance rates, the rate of fecal pellet production as well as respiration rates to check on the metabolic needs of this copepod. Winter and summer rates of feeding were compared. I seek an accurate measure of the feeding habits of this copepod that permit its survival within the planktonic community of the Antarctic.

\section{Material and methods}

\section{Copepod collections}

Three field seasons were spent working in the Antarctic peninsula region. Between December 1985 and February 1986, February to April 1988. and June through August 1989, zooplankton samples were taken off the research vessel POLAR DUKE in Croker Passage at $64^{\circ} 05^{\prime} \mathrm{S}$ latitude, $61^{\circ} 50^{\prime} \mathrm{W}$ longitude. A single-level opening-closing net, consisting of two nets having mesh sizes of $500 \mu \mathrm{m}$ and $250 \mu \mathrm{m}$, attached side by side, with square mouth openings of $0.5 \mathrm{~m}^{2}$, was used to collect zooplankton in oblique hauls. The closed net was lowered to $1000 \mathrm{~m}$, opened and gently retrieved at $10 \mathrm{~m} / \mathrm{min}$ at a ship's speed of 1-2 knots. At $600 \mathrm{~m}$, the net was closed and brought to the surface at $20 \mathrm{~m} / \mathrm{min}$. The collecting time from $1000-600 \mathrm{~m}$ of the open net was 40 to 50 minutes followed by an additional 30 minutes for net retrieval. Late developmental stages of Euchaeta antarctica were sorted from the largevolume ( 5 liters) collecting cup attached to the $500 \mu \mathrm{m}$-mesh net. These predators were placed immediately either in $30-\mathrm{ml}$ vials to collect their fecal pellets, or in buckets of $35 \mu \mathrm{m}$-filtered surface seawater kept in a running seawater tank at the ambient temperature between -1 and $2^{\circ} \mathrm{C}$, and returned later to the laboratory for feeding experiments. To prevent large predators from decimating the plankton collected in the small mesh $(250 \mu \mathrm{m})$ hauls, large plankters were removed by gently pouring the contents of the collecting cup through a $3 \mathrm{~mm}$-mesh screen partially submerged into a bucket of 35- $\mu \mathrm{m}$-filtered surface seawater. These small plankton were brought back to the laboratory where I separated food organisms (Metridia, Euchaeta juveniles. Oithona, Oncaea, Microcalanus, various nauplii) for feeding experiments. The laboratory is located at the U.S. facility, Palmer Station, on the Antarctic peninsula at $64^{\circ} 46^{\prime} \mathrm{S}, 64^{\circ} 03^{\prime} \mathrm{W}$. It is equipped with running seawater tables and a constant temperature room. At the laboratory, copepods were kept either in the water tables in dim light or in the cold room in the dark at $0^{\circ} \mathrm{C}$. Additional collections of copepods (both predators and prey) were possible from Palmer Basin at $64^{\circ} 57^{\prime} \mathrm{S}$, $64^{\circ} 31^{\prime} \mathrm{W}$, a site less than a mile south of the station.

\section{Conditions of feeding experiments}

To initiate a feeding experiment, 1-2 predators were placed into a jar varying in volume from 1 to 20 liters filled with $0.22 \mu \mathrm{m}$-filtered seawater. To this container was added a known number of prey organisms. Five to 8 replicates were set up as well as 1-2 controls where no predators were added. Controls indicated that natural mortality was minimal and counting accuracy was good. The difference between the number of prey before and after exposure to the predators gave a measure of feeding rates (see Yen 1982 for details). All predators were selected haphazardly from a stock culture containing predators at 5/liter with prey levels maintained above 5/liter. Predators were grouped according to the date on which they were collected. Feeding rates were measured on predators kept for no longer than two weeks after capture from the field.

To establish an experimental procedure that would measure feeding rates as accurately as possible, each set of experimental containers and controls was subjected to the following conditions: 1) The lighting conditions were varied between two levels: dark versus a light intensity that was $12 \%$ of the midday surface light irradiance in midsummer; 2) The mixing regime was varied between unmixed versus mixing by rotation of the jar along its long axis at approximately 1$2 \mathrm{rpm}$; 3) To ascertain diel patterns, feeding rates were measured in the dark over 12 hours during the day $(0900-2100 \mathrm{~h})$ and 12 hours during the night $(2100-0900 \mathrm{~h})$. These following experiments then were run over 24 hours in the dark on a mixing device; 4) Feeding rates were measured when predators were offered, in separate containers, live versus heat-killed copepod prey; 5) Under anesthesia, the first antennae of the predatory copepods were clipped off near the base 
and kept for 3 days. Little mortality occurred. Feeding rates of these predators were compared to rates of intact predators offered the same prey type; 6) Feeding rates were measured of predators acclimated for 3 days at temperatures from -1.8 to $+1.5^{\circ} \mathrm{C}$, covering the range experienced by the copepods in this Antarctic environment; 7) Feeding experiments were performed during the austral summer, autumn, and winter to ascertain seasonal variations.

\section{Size-selective feeding experiments}

Prey of various sizes were offered in single-species groups at $25 \mathrm{prey} /$ liter in one-liter containers with 1-2 predators/liter. Even at this high prey concentration, predators could consume in some cases all prey offered; hence, although feeding rates may have been restricted, the pattern describing the difference in rates on different species could still be discerned. Experiments were run for 24 hours in the dark on a mixing device; these are now the standard conditions for all subsequent feeding experiments. Feeding rates on at least three prey types were measured simultaneously. When the experiments were run again using three prey types, feeding rates were measured on at least one of the prey types measured previously to assure that no overall change in feeding rates occurred. No marked change in feeding rates was noted between selective feeding trials. Measurements of copepod prosome lengths were taken where live copepods were anesthetized and measured under a Wild dissecting microscope. Measurements also were taken of the length of the second basipodal segment of the maxilliped, the primary appendage used in prey capture by species of Euchaetidae (Yen 1985).

\section{Functional response of starved and fed predators}

Using prey of the preferred size, as determined in the above size-selective feeding experiments, a series of feeding experiments at various prey concentrations was run. Usually, three concentrations were examined simultaneously. When other concentrations were tested, at least one concentration, duplicating one of the previously tested concentrations, was measured again to see if any general change had occurred in feeding rates. No general change was seen over the week that these experiments were performed. Prosome lengths of the prey before and after each of these experiments were measured to determine if any selection occurred over the small size range within a single species. No significant change in the size composition was noted. The change in feeding rates with increasing food concentration described the functional response. The saturation feeding rate, where increases in food concentration would not cause an increase in rates, was ascertained. Clearance rates were determined as in Frost (1972). Clearance rates can be considered the volume effectively searched by a predatory copepod. Container volume was chosen to maintain a similarity in the total number of prey offered to the predators: at 1/liter, 20-liter carboys were used; at 5/liter and 10/liter, 4-liter jars were used; at all concentrations greater than or equal to 25/liter, 1-liter jars were used (Yen 1983).

Feeding rates at 50 prey/liter of starved and fed aduit female predators as well as copepodid Stages IV and V were measured on two prey types varying in size: Metridia gerlachei juveniles at $1149.4 \mu \mathrm{m} \pm 12.1 \%$ (coefficient of variation for $\mathrm{n}=19)$ and Microcalanus adults at $531.0 \mu \mathrm{m} \pm 3.9 \%$ (C.V. for $n=17$ ). Fed predators had been recently captured (within one week) and kept in stock cultures; the concentration of small copepods added as prey was kept above 5/liter. Other predators were starved in filtered seawater over a three-week period.

\section{Fecal pellet production rates in situ and in the laboratory}

Predators collected from Croker Passage that appeared to have full guts were separated from the plankton tow and placed immediately into individual $30-\mathrm{ml}$ vials; after 24 hours, the contents of these vials were preserved and the number of fecal pellets enumerated. The total number of pellets produced in situ was determined in this way. In the laboratory, predators were fed their preferred prey overnight and predators with full guts then were placed into individual $30-\mathrm{ml}$ vials. The number of fecal pellets produced every 12 hours was noted until no more pellets were produced. Fecal pellet production rates were determined from these experiments.

Gut evacuation by copepods is generally illustrated by plotting the amount of chlorophyll initially within the gut and following the decline over time in gut fullness (Dagg \& Wyman 1983). 
Since a carnivorous copepod does not have the chlorophyll pigment to trace this decline, I have monitored fecal pellet production instead. To illustrate gut evacuation by a predatory copepod. the total number of fecal pellets evacuated was plotted as the initial time point, representing a full gut. As fecal pellets were produced, the total number to be evacuated declined over time, representing a gut that was emptying. The rate of fecal pellet production was determined by fitting the gut evacuation curves to a line where the slope is the pellet production rate.

In another set of laboratory experiments, a known number of prey was ingested by a known number of starved predators, and all the fecal pellets produced during the experiment plus those pellets produced over 24 hours after placing the predators into filtered seawater were collected. A conversion factor was determined from the ratio of prey consumed to the total number of fecal pellets produced. In this case, the conversion factor for only the preferred prey was determined. The live copepods, both predator and prey, were anesthetized for prosome length measurements, then rinsed briefly in distilled water and freezedried. The weights of the dried copepods were measured using a Cahn Electrobalance. The length and width of the fecal pellets were also measured. A known number of pellets were rinsed briefly in distilled water and dried on a preweighed filter. The dry weight of the filter plus pellets minus the dry weight of the filter gave an estimate of the dry weight of the fecal pellets.

\section{Respiration rates}

To check that the ingestion rates compensate for metabolic costs, respiration rates were measured using the Strathkelvin oxygen meter (Model 781) which utilizes a Clark-type polarographic microcathode electrode to measure oxygen content. Three predators were placed into a $56-\mathrm{ml}$ container of $0.22 \mu \mathrm{m}$ filtered seawater kept at $0^{\circ} \mathrm{C}$. The electrode was sealed into the container and the amount of oxygen in the water was recorded over a 6 to 8 hour period. The rate of decline in the concentration of oxygen in the seawater gave an estimate of respiration rates of the copepods. Respiration rates were converted to $\mu \mathrm{g} \mathrm{C}$ catabolized according to Parsons et al. (1979), using an RQ of 0.75 . To convert to dry weight, a ratio of $40 \%$ carbon/dry weight was used.

\section{Results}

\section{Sources of variability in feeding rates (Table 1)}

Adult female Euchaeta antarctica did not produce any fecal pellets when fed either a concentrated mixture of natural phytoplankton or a pure culture of centric diatoms. Adult males also did not produce any fecal pellets when fed phytoplankton. They also did not consume any copepod prey. Males of this species have degenerate mouthparts and do not feed. Little difference was seen in feeding rates of the adult female copepod in mixed

Table 1. Feeding rates of the predatory copepod Euchaeto antarctica under varying conditions.

\begin{tabular}{|c|c|c|c|}
\hline Conditions & Prey/day S.E. & $\mathrm{n}$ & Prey concn; predator stage \\
\hline Dark mixed & $9.08 \pm 1.27$ & 6 & 25 Metridia/liter, CVIq \\
\hline Dark unmixed & $10.0 \pm 0.29$ & 4 & \\
\hline Light mixed & $9.64=1.02$ & 7 & \\
\hline Light unmixed & $5.0 \pm 1.12$ & 5 & \\
\hline Night of 5 Jan & $2.07 \pm 2.33$ & 7 & 25 Metridia/liter, CV \\
\hline Day 6 Jan & $4.00 \pm 1.87$ & 7 & \\
\hline Night 6 Jan & $4.10 \pm 1.98$ & 5 & \\
\hline Day 7 Jan & $4.29 \pm 2.06$ & 7 & \\
\hline Live prey & $6.2 \pm 1.6$ & 5 & 20 Microcalanus/liter, CVIQ \\
\hline Heat-killed prey & $0.7 \pm 0.8$ & 5 & \\
\hline$w / o$ antennae on predator & 0.0 & 5 & \\
\hline$-1.8^{\circ} \mathrm{C}$ & $7.8 \pm 5.1$ & 5 & 50 Oncaea/liter, CV \\
\hline $1.5^{\circ} \mathrm{C}$ & $+9 \pm 4.2$ & 5 & \\
\hline$-1.8^{\circ} \mathrm{C}$ & $14.5 \pm 9.8$ & 4 & 50) Microcalanus/liter, CVIQ \\
\hline $1^{\circ} \mathrm{C}$ & $13.0 \pm 8.2$ & 5 & \\
\hline
\end{tabular}


Table 2. Prosome lengths of prey species used in selective feeding experiments.

\begin{tabular}{lcc}
\hline Prey species & Mean $(\mu) \mathrm{C} . \mathrm{V}$. & $\mathrm{n}$ \\
\hline Metridia gerlachei & $2500.1 \pm 4.4 \%$ & 16 \\
Metridia gerlachei & $1699.5 \pm 8.7 \%$ & 15 \\
Metridia gerlachei & $1555.5 \pm 7.4 \%$ & 27 \\
Metridia gerlachei & $1459.0 \pm 10.9 \%$ & 12 \\
Metridia gerlachei & $1149.5 \pm 12.1 \%$ & 19 \\
Metridia gerlachei & $1117.5 \pm 10.0 \%$ & 13 \\
Euchaeta juveniles & $1111.5 \pm 21.3 \%$ & 16 \\
Oncaea & $754.5 \pm 3.9 \%$ & 13 \\
Oithona & $726.1 \pm 3.1 \%$ & 17 \\
Microcalanus & $531.0 \pm 3.9 \%$ & 17 \\
Microcalanus & $496.7 \pm 7.0 \%$ & 20 \\
Oncaea & $425.7 \pm 4.9 \%$ & 15 \\
Oncaea females & $391.3 \pm 27.0 \%$ & 42 \\
Oncaea males & $318.3 \pm 7.9 \%$ & 22 \\
Nauplii & $318.3 \pm 24.4 \%$ & 24 \\
\hline
\end{tabular}

versus unmixed containers. Little difference was noted in feeding rates of copepods in mixed containers in the light versus the dark. However, a reduction in feeding rates in the light was noted when the containers were unmixed. Hence, all subsequent experiments were performed in the dark. The containers also were mixed to maintain an even prey distribution without clumping even though the copepod prey are mobile. Although little difference was noted in day versus nighttime feeding rates in the mid-summer season, all subsequent experiments were performed over 24 hours to avoid any possible diel effects. Heatkilling the prey and removing the first antennae on the predator caused a cessation in feeding on animal prey. This suggests that movement may be necessary for prey detection by this Antarctic species of Euchaeta, as has been found for other congeners (Yen 1982, 1987). The first antennae also appear to be necessary for predatory feeding as has been found for other copepods (Mullin \& Brooks 1967; Landry 1980). Care was taken to use lively prey and intact predators in all experiments. Temperature changes of over $3^{\circ} \mathrm{C}$, within the range found in Croker Passage, did not alter the feeding rates of adult female predators nor of the copepodid Stage $V$ feeding on smaller copepod prey at $50 \mathrm{prey} / \mathrm{liter}$. It is possible that at these high food concentrations, a temperature effect on feeding rates would be masked (Williamson \& Butler 1987). In July and August, I found that the adult female copepods did not consume copepods nor did they produce fecal pellets as observed

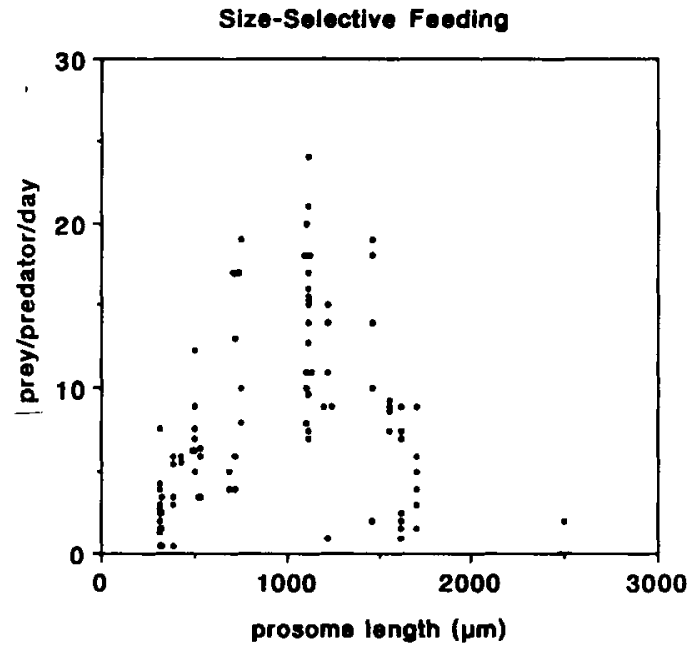

Fig. 1. Predatory feeding rates of adult female Euchaeta antarctica offered prey of varying prosome lengths (see Table 2) at 25 prey/liter. These experiments were done during the two summer seasons.

in the summer months (Dec-Apr). All feeding experiments therefore describe summer feeding activity.

\section{Size selective feeding}

Daily rates of predation by adult female $E$. antarctica were measured on several copepod prey varying in size (Table 2). Highest predation rates were achieved on prey having a prosome length of approximately $1200 \mu \mathrm{m}$ (Fig. 1). Low feeding rates were measured on copepod prey larger than $1700 \mu \mathrm{m}$ or smaller than $500 \mu \mathrm{m}$. Low feeding rates on large prey may be caused by ineffective handling of large prey while low feeding rates on small prey may be caused by inability to detect the small movements created by them.

\section{Functional response}

Feeding rates increased with increasing food concentration (Fig. 2). The mean saturation feeding rate of the adult female predatory copepods feeding on prey of the preferred size, Metridia gerlachei juveniles, was $18.7 \mathrm{prey} / \mathrm{predator} / \mathrm{day}$. A 3-week starvation period of the adult female predator caused a slight increase in feeding rates on M. gerlachei (Fig. 3A). Copepod Stages V and IV feeding on the same prey type fed at lower rates of $60 \%$ and $20 \%$, respectively, of the satu- 
Functional Response

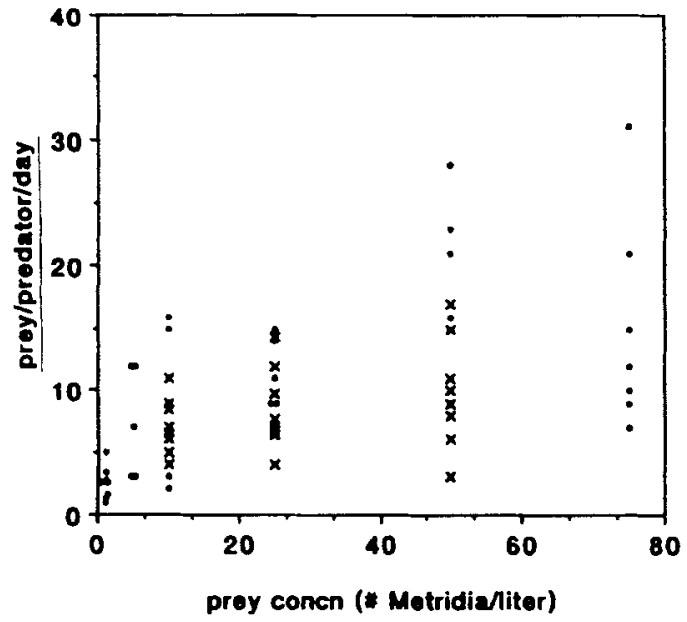

Fig. 2. Predatory feeding rates of adult female Euchaeta antarctica offered juvenile Metridia gerlachei at various prey concentrations. (solid circles $=3-4$ Jan 1986. $\mathrm{PL}=1224.3 \mu \mathrm{m} \pm$ $16 \% \mathrm{w} / \mathrm{n}=42 ; \mathrm{x}=7$ Feb 1986. PL $=1438.1 \mu \mathrm{m} \pm 9.3 \%$ $\mathrm{w} / \mathrm{n}=28)$.

ration feeding rates of the adult female stage. The two older stages ingested around $9 \%$ of their bodily weight each day while the younger CIV stage was able to ingest over $20 \%$ of their body weight per day on this prey type (Table 3 ).

In contrast, when feeding rates of these stages were measured on prey that were half the size of the preferred prey of the adult female predator, namely Microcalanus at $500 \mu \mathrm{m}$ (Fig. 3B), highest rates were achieved by the smallest developmental stage (CIV) at $17 \mathrm{prey} /$ predator/day. Copepodid Stages V and VI fed at lower rates of $74 \%$ and $39 \%$, respectively, of the feeding rates of the copepodid Stage IV. The copepodid Stage IV were able to ingest $11 \%$ of their bodily weight per day on this prey type while the CV and CVI stages could get only around $1 \%$ of their bodily weight on this small copepod (Table 3). A threeweek starvation period did not produce a marked change in the feeding rates on this prey type.

Maximum clearance rates of the adult female predatory copepod on its preferred prey obtained at 1 prey/liter was $101.9 \mathrm{ml} /$ female $/ \mathrm{h}$ or 2.4 liters/ d. This is similar to that of the adult female temperate copepod E. elongata (3.4 liters/d; Yen 1985 ) and that of Labidocera trispinosa (2.7 liters/ d; Landry 1978) but much higher than the maximum clearance rates of other copepods (Cory-
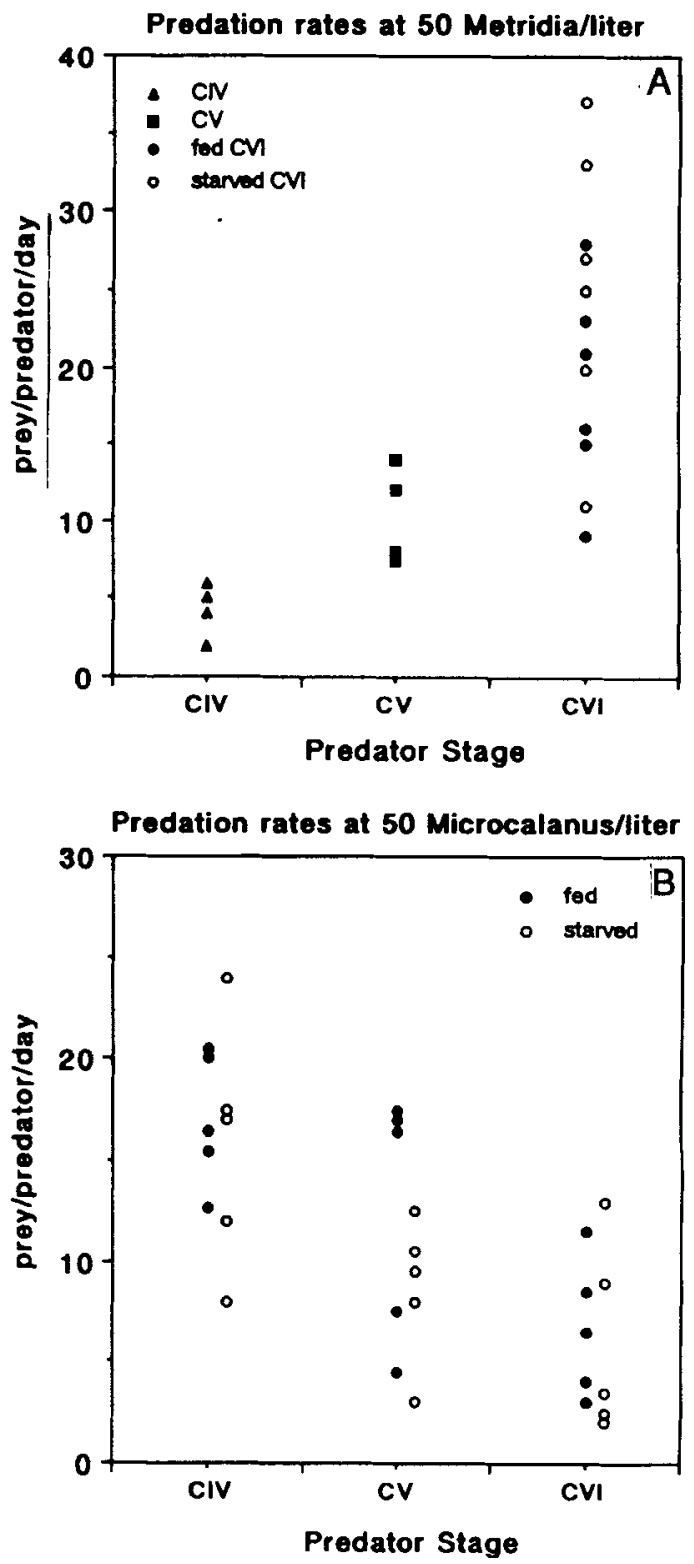

Fig. 3. A) Predatory feeding rates of three developmental stages (copcpodid Stages IV. V. VI females) of Euchaeta antarctica on juvenile Metridia gerlachei $(-1200 \mu \mathrm{m}$ PL) at 50 prey/liter. Feeding rates of starved (open circles) and fed (solid circles) adult females are compared. B) Predatory feeding rates of starved (open circles) and fed (solid circles) developmental stages of Euchaeta antarctica on Microcalanus spp. $(-50) \mu \mathrm{m}$ PL) at $50 \mathrm{prey} / \mathrm{liter}$

caeus anglicus at 0.004 liters/d, Neocalanus cristatus at 0.5 liters/d, Oithona spinirostris at 0.045 liters/d, or Calanus pacificus at 0.65 liters/ day; from Landry \& Fagerness 1988). 
Table 3. Proportion of bodily weight consumed and proportion of ingested weight respired by 3 developmental stages of Euchaeta antarctica fed 2 prey types at 50/liter: Metridia gerlachei and Microcalanus.

\begin{tabular}{|c|c|c|c|c|c|c|}
\hline \multirow[b]{2}{*}{ Stage } & \multirow{2}{*}{$\begin{array}{l}\text { Dry weight } \\
(\mu \mathrm{g})\end{array}$} & \multirow{2}{*}{$\begin{array}{l}\text { Respiration } \\
\mu l \mathrm{O}_{2} / \operatorname{cop} / \mathrm{h}\end{array}$} & \multicolumn{2}{|c|}{$\%$ Bodily wt consumed $/ \mathrm{d}^{+}$} & \multicolumn{2}{|c|}{$\%$ Ingested wt respired/d } \\
\hline & & & on $\mathrm{Met}^{6}$ & on $\mu \mathrm{Cal}^{\top}$ & on Met & on $\mu \mathrm{Cal}$ \\
\hline CVI & $5709 \pm 16 \%$ & 3.9 & 9.3 & 0.4 & 17.8 & 413.0 \\
\hline $\mathrm{CV}$ & $3409 \pm 8 \%{ }^{2}$ & 2.0 & 9.2 & 1.3 & 15.4 & 113.0 \\
\hline CIV & $500 \pm 9.5 \% \%^{3}$ & 1.0 & 21.5 & 11.6 & 22.3 & 41.5 \\
\hline
\end{tabular}

${ }^{1}$ Coefficient of Variation (C.V.) for $n=4$ groups of 20 individuals.

${ }^{2} \mathrm{C} . \mathrm{V}$. for $\mathrm{n}=7$ groups of $2-12$ individuals.

${ }^{3}$ C.V. for $n=6$ groups of $10-32$ individuals.

${ }^{4}$ As depicted in Fig. 3.

${ }^{5}$ Using the equations of Parsons et al. (1979), assuming an R.Q. of 0.75 and a ratio of $40 \% \mathrm{C} / \mathrm{DW}$

${ }^{6}$ Dry Weight of Metridia $=28.3 \mu \mathrm{g} \pm 10.2 \%$ ( $\mathrm{n}=3$ groups of 25 individuals).

${ }^{7} \mathrm{DW}$ of Microcalanus $=3.4 \mu \mathrm{g}(\mathrm{n}=1$ group of 100 individuals $)$.

\section{Respiration rates}

During March 1988, adult female copepods respired an average of $3.83 \mu \mathrm{l} \mathrm{O} /$ female/h while juvenile stage $\mathrm{CV}$ respired $2.0 \mu \mathrm{l} \mathrm{O}_{2} / \mathrm{h}$ and $\mathrm{CIV}$ respired $1.0 \mu \mathrm{l} \mathrm{O} / \mathrm{h}$ (Table 3).

\section{Fecal pellet production}

Gut fullness showed a uniform decline over time (Fig. 4A). Fecal pellets were produced at a rate of 0.7 pellets $/ h$ for laboratory-fed predators and no trend was noted in pellet production rates for predators having different levels of gut fullness (Fig. 4B). Since Euchaeta does not feed on heatkilled copepods, I presumed that it did not consume fecal pellets and no precautions were taken to prevent copraphagy. Furthermore, over the collection period, a maximum of 0.9 pellets could have been produced by some of the copepods, so some measurements may have been underestimated. Pellets were uniform in size, having a length of $930 \mu \mathrm{m}$ and width of $180 \mu \mathrm{m}$ giving an estimated cylindrical volume of $23.7 \mu \mathrm{l}$ (Table 4). An average full gut of $E$. antarctica can produce about 10 fecal pellets, giving an estimated gut volume of $237 \mu \mathrm{l}$. When fed their preferred prey, the adult female predator produced one fecal pellet from 1.63 consumed prey. Assuming the rate of egestion is equal to the rate of ingestion, this factor was used to convert pellet production rate to an ingestion rate of 1.14 prey/ hour. In order to reach maximum ingestion rate, this copepod would have to feed for 16.5 hours. However, only 2.8 hours of feeding is required to cover their metabolic costs.

\section{Discussion}

During the austral summer period, adult female Euchaeta antarctica appears to be an exclusive carnivore, capable of consuming up to 20 mobile copepod prey/predator/d and scanning up to 2.4 liters/d. These rates were measured using copepods of Metridia gerlachei, prey of the preferred size of approximately $1200 \mu \mathrm{m}$. These preferred prey also happen to be one of the most abundant copepods available in the plankton, with CIIIs available in December and CIVs available through March; later in the summer, Microcalanus becomes abundant in the plankton (Yen \& Zmijewska unpubl.). These smaller copepod prey apparently are more efficiently consumed by smaller than larger developmental stages of the predator. A similar shift in the size of preferred prey with predator size has been seen both intraspecifically for the various developmental stages of the temperate species (Yen 1985) as well as interspecifically for Euchaeta of different sizes (Yen pers. obsns). The size of the preferred prey of $E$. antarctica is approximately $65 \%$ the length of the basipod $(1835 \mu \mathrm{m}$; see Table 4). This further confirms the $70 \pm 5 \%$ ratio of primary prey size to basipod length found for the temperate congener ( $E$. elongata of $72 \%$; Yen 1985 ) as well as for other euchaetids ( $E$. norvegica at $64 \%$, E. rimana at $71 \%$; Yen unpubl.).

At a mean saturation ingestion rate of 18.7 prey/d on $M$. gerlachei, weighing $28.3 \mu \mathrm{g}$ dry weight, $8.83 \%$ of the $6 \mathrm{mg}$ body weight of the adult female predator is consumed (Table 4). Of this ingested material, only $17.3 \%$ is required for respiratory costs, assuming an R.Q. of 0.75 


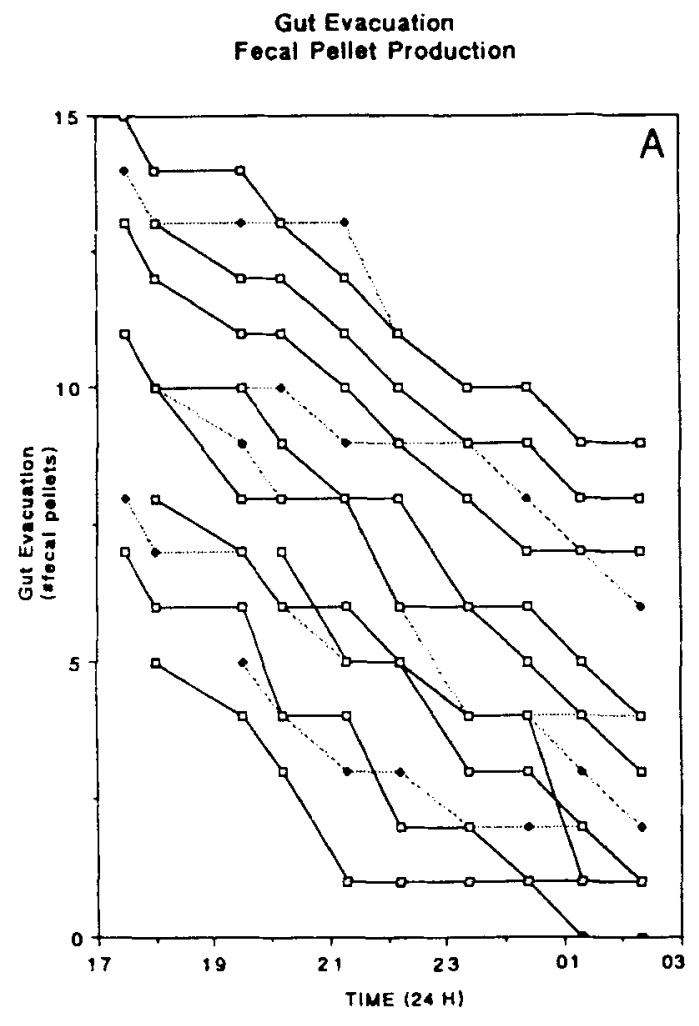

Fig. 4. A) Gut evacuation curves of it individual adult female Eluchacte antarstica fed wernight in the lahoratory on a mixed prey assemblage and monitured for fecal pellet production over 10 hours. B) Fecal pellet production rates (pellew hour) as determined from the shope of the line fit to the gut evacuation curves shown in $A$. The average rate of $0.697 \pm 0.157$ pellets hour showed noconsistent variation with respect to gut fullness (expressed as teral number of fecal peldets evacuated). () Total number of fecal pellets cevacuated per individual by adult female Euchacta antarctica collected directly from Croker Pasage.

(Parsons et al. 1979). Of the copepods collected directly from Croker Passage that had material visible in their gut (Fig. 4C). 11\% evacuated over 11 fecal pellets which converts to 18 prey consumed: these predators had achieved the lahoratory-determined saturation ingestion rate. Ninety-six percent of these predators evacuated more than 2 pellets which means nearly all of them consumed enough to cover their respiratory needs. Most of these copepods $\left(-40 c_{i}\right)$ evacuated $3-5$ fecal pellets which converts to 5-8 prey consumed. This in situ meal more than adequately covers their daily respiratory costs.

Compared to the older developmental Stages $\mathrm{CV}$ and CVI, the younger developmental Stage

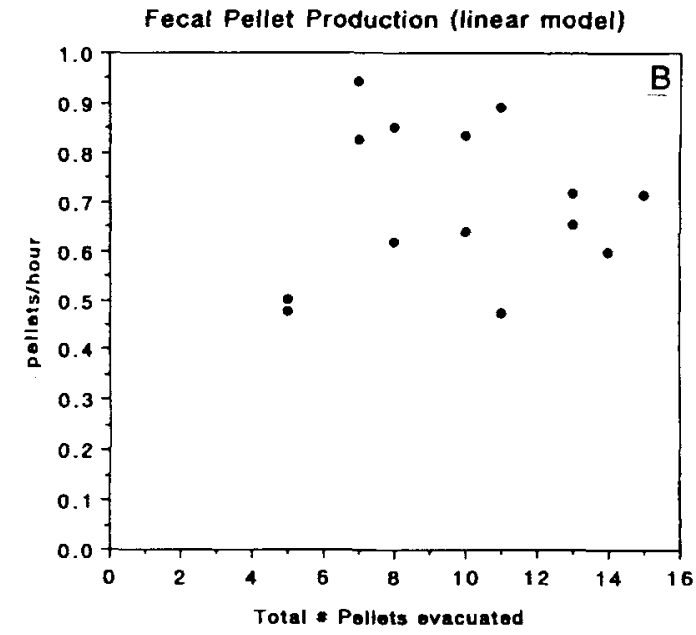

In situ Fecal Pellet Production

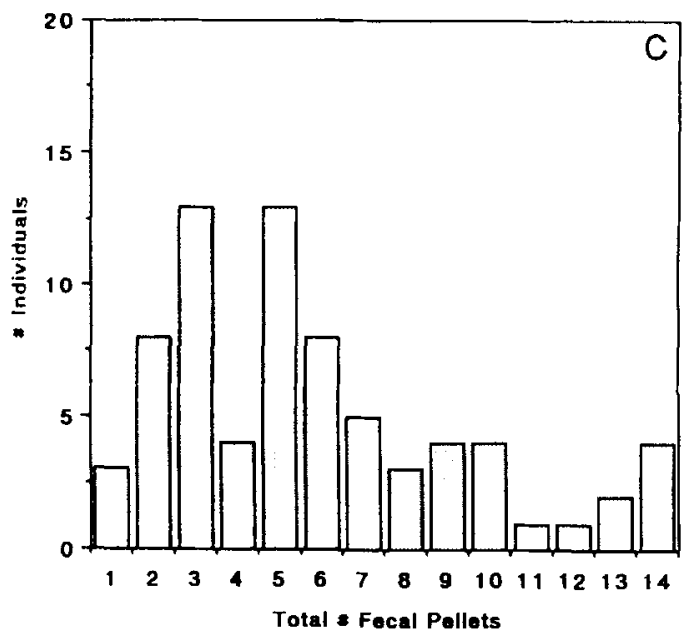

CIV consumed a fewer number of the large prey (Metridia) and more of the smaller prey (Micro(alanus). Yet on both prey types, this young and potentially faster growing stage obtained $10 \%$ more of its bodily weight per day than could be obtained by the older, mature individuals of the same species (Table 3). Furthermore, while the younger stages were able to meet their metabolic costs on either prey type, the older stages could meet their metabolic costs only on the larger prey. Older individuals may not be able to find enough food late in the season, when the juvenile stages of Metridia no longer are available, which could force them to go into their overwintering state. Little feeding and fecal pellet production 
Table 4. Characteristics of the predatory copepod Euchaeta antarctica and its feeding ecology (from Croker Passage, Antarctica; $\left.64^{\circ} 05^{\prime} \mathrm{S}, 62^{\circ} 50^{\prime} \mathrm{W}\right)$.

\begin{tabular}{|c|c|c|c|c|}
\hline & & Mean & $\mathrm{n}$ & Units \\
\hline CVI female DW & $\begin{array}{l}6.0 \\
7.0\end{array}$ & $\begin{array}{l} \pm 0.54 \text { C.I. } \\
\pm 3.9 \%\end{array}$ & (16) & $\mathrm{mg}$ \\
\hline Prosome length & C.V: & & (12) & $\mathrm{mm}$ \\
\hline Basipod length (B2) & 1835 & $\pm 6.5 \%$ & (12) & $\mu \mathrm{m}$ \\
\hline $1^{\circ}$ Prey length (PL) & 1200 & & & $\mu \mathrm{m}$ \\
\hline$\% \mathrm{~B} 2 / \mathrm{PL}$ & $65 \%$ & & & \\
\hline Saturation I & 18.7 & \pm 6.7 & (6) & $\operatorname{prey} / Q /$ day \\
\hline$\% \mathrm{BW}$ ingested & $8.83 \%$ & & & \\
\hline Saturation CL & 101.9 & \pm 59 & & $\mathrm{ml} / q /$ hour \\
\hline Volume searched & 2.4 & & & liter/Q/day \\
\hline Respiration rate & 3.83 & \pm 0.43 & (6) & u) $\mathrm{O}_{2} / \mathrm{Q} /$ hour \\
\hline$\% \mathrm{I}_{\mathrm{mx}}$ respired & $17.3 \%$ & & & \\
\hline Prey: $M$. gerlachei & 1149.5 & $5 \pm 12.1 \%$ & (19) & $\mu \mathrm{m}$ \\
\hline Dry Wt prey & 28.3 & \pm 2.9 & (3) & $\mu \mathrm{g}$ \\
\hline Dry Wt fecal pellet & 3.5 & $\pm 16.2 \%$ & (2) & $\mu \mathrm{g}$ \\
\hline Length of pellet & 931.8 & $\pm 15.5 \%$ & (14) & $\mu \mathrm{m}$ \\
\hline Width of pellet & 180.0 & $\pm 9.0 \%$ & (14) & $\mu \mathrm{m}$ \\
\hline Volume of pellet & 23.7 & & & $\mu 1$ \\
\hline Maximum \# pellets & 10 & & & \\
\hline Gut volume & 237 & & & $\mu l$ \\
\hline Pellet production rate & 0.69 & \pm 0.157 & (14) & pellets/hour \\
\hline Conversion factor & 1.63 & \pm 0.21 & (6) & prey/pellet \\
\hline In situ ingestion & 1.14 & & & prey/hour \\
\hline
\end{tabular}

occurred in the wintertime. Since temperature had little effect on feeding rates, this strong seasonal change in feeding rate may reflect the strong seasonal change in food availability, a response regulated by the extremes in the light cycle at these high latitudes. Seasonal responses have been documented in other high-latitude copepods (Båmstedt \& Ervik 1984; Båmstedt \& Tande 1988; Grønvik \& Hopkins 1984; Head \& Harris 1985). According to their findings, Calanus, an obligate herbivore, appears to feed actively and to accumulate lipids in the summer and then go into an overwintering inactive state; energy for reproduction in the spring is derived from its reserves. Metridia, an omnivore, does not accumulate lipid, remains active further into the winter period, yet relies on the spring bloom to provide energy for its spring reproduction. This dichotomy, in part, has been attributed to trophic type. Accordingly, E. antarctica, a carnivore, ought to continue to feed actively during the winter season. My findings indicate that $E$. antarctica responds in a way similar to Calanus: it stops feeding during winter and relies on accumulated lipids for reproductive activity, which occurs during the winter (Littlepage 1964). This response appears independent of trophic type but dependent on the seasonality in food supply. The omnivore, Metridia, is able to feed on both phytoplankton and microzooplankton, and relies on a less variant supply of food. In contrast, Calanus, which feeds on phytoplankton, is subject to extreme seasonality in its food supply. Euchaeta, which feeds on mobile prey of a preferred size $(1.2 \mathrm{~mm})$, also appears subject to a limited food supply in winter. Its potential prey include the large population of overwintering copepods. However, overwintering herbivorous copepods usually are very sluggish (Hallberg \& Hirche 1980). Without movement, E. antarctica may not be able to detect these prey. The overwintering stages also are the late copepod stages and may be far larger than the preferred prey size. Furthermore, preliminary analyses indicate that $E$. antarctica reduced its migratory activity in winter and the population tended to remain below $600 \mathrm{~m}$ (Yen \& Zmijewska unpubl.). At these depths, its distribution may not overlap with that of its prey. In response to this deprivation of food, Euchaeta ceases to feed in winter as does Calanus. Low winter activity is a behavior of the herbivorous as well as the carnivorous copepods. 
The other trait that accompanies overwintering, lipid accumulation, also appears to be a response to large variations in food supply (Lee et al. 1971). Euchaeta antarctica is capable of storing reserves as is evident by its high lipid content (Littlepage 1964). The adequacy of these lipid stores in providing the energy necessary for winter activity (metabolic and reproductive requirements) needs further investigation.

Acknowledgements. - I thank the assistance of R. P. Hassett. M. I. Zmijewska, C. Faggiani, M. Bailiff, and J. Finn during the research periods in Antarctica. I thank the personnel on board the R/V POLAR DUKE and at Palmer Station for providing good working conditions. I thank $P$. Ward and an anonymous reviewer for their comments. Support for this research came from the National Science Foundation. Division of Polar Programs DPP-8415395 and DPP-8613957, awarded to J. Yen. Contribution No. 806 from the Marine Sciences Research Center. State University of New York at Stony Brook

\section{References}

Bradford. J., Haakonssen. L. \& Jillett. J. B. 1983: The marine fauna of New Zealand: Pelagic calanoid copepods: Families Euchaetidac, Phaennidae. Scolecithricidae, Diaixidac, and Tharybidae. N. Zealand Oceanogr. Mem. $90.146 \mathrm{pp}$.

Båmstedt, U. \& Ervik, A. 1984: Local variations in size and activity among Calanus finmarchicus and Metridia longa (Copepoda, Calanoida) overwintering on the west coast of Norway. J. Plankton Res. 6. 843-857.

Båmstedt. U. \& Tande. K. 1988: Physiological responses of Calanus finmarchicus and Metridia longa (Copepoda: Calanoida) during the winter-spring transition. Mar. Biol. 99. 31-38.

Dagg. M. J. \& Wyman. K. D. 1983: Natural ingestion rates of the copepods Neocalanus plumchrus and N. cristatus calculated from gut contents. Mar. Ecol. Prog. Ser. 13, 37-46.

Dearborn, J. H., Ferrari. F. D. \& Edwards, K. C. 1986: Can pelagic aggregations cause benthic satiation? Feeding biology of the antarctic brittle star Astrotoma agassizii. Biology of the Antarctic Seas XVII. Ant. Res. Ser. 44, 1-27

Frost, B. W. 1972: Effects of size and concentration of food particles on the feeding behavior of the marine planktonic copepod Calanus pacificus. Limnol. Oceanogr. 17. 805-815.

Grønvik. S. \& Hopkins. C. C. E. 1984: Ecological investigations of the zooplankton community of Balsfjorden, northern Norway: Generation cycle. seasonal vertical distribution. and seasonal variations in body weight. and casbon and nitrogen content of the copepod Metridia longa (Lubbock). J. Exp. Mar. Biol. Ecol. 80. 93-107.
Hallberg, E. \& Hirche, H.-J. 1980: Differentiation of mid-gut in adults and overwintering copepodids of Calanus finmarchicus (Gunnerus) and C. helgolandicus Claus. J. Exp. Mar. Biol. Ecol. 48. 283-295.

Head. E. J. H. \& Harris. L. R. 1985: Physiological and biochemical changes in Calanus hyperboreus from Jones Sound NWT during the transition from summer feeding to overwintering condition. Polar Biol. 4, 99-106.

Hopkins. T. L. 1985a: Food web of an Antarctic midwater ecosystem. Marine Biol. 89. 197-212.

Hopkins, T. L.. 1985b: The zooplankton community of Croker Passage. Antarctic Peninsula. Polar Biol. 4, 161-170.

Landry, M. R. 1978: Predatory feeding behavior of a marine copepod. Labidocera trinspinosa. Limnol. Oceanogr. 23. 1103-1113.

Landry, M. R. 1980: Detection of prey by Calanus pacificus: Implications of the first antennae. Limnol. Oceanogr. 25. 545-549.

Landry, M. R. \& Fagerness, V. L. 1988: Behavioral and morphological influences on predatory interactions among marine copepods. Bull. Mar. Sci. 43, 509-529.

Lee R. F., Hirota. J. \& Barnett, A. M. 1971: Distribution and importance of wax esters in marine copepods and other zooplankton. Deep-Sea Res. 18, 1147-1165.

Littlepage. J. L. 1964: Seasonal variation in lipid content of two Antarctic marine crustacea. Pp. 463-470 in Carrick, R., Holgatc, M. \& Prevost. J. (eds.): Biologie Antarctique. Hermann, Paris.

Mullin. M. M. \& Brooks. E. R. 1967: Laboratory culturc. growth rate. and feeding behavior of a planktonic marine copepod. Limnol. Oceanogr. 12,657-666.

Park. T. 1978: Calanoid copepods belonging to the families Aetideidae and Euchactidac from Antarctic and Subantarctic waters. Biology of the Antarctic Seas VIl. Ant. Res. Ser. 27. 290 pp.

Parsons, T. R., Takahashi, M. \& Hargrave, B. 1979: Biological oceanographic processes. 2nd ed. Pergamon Press. New York. $332 \mathrm{pp}$.

Williamson. C. E. \& Butler. N. M. 1987: Temperature, food and mate limitation of copepod reproductive rates: Separating the effects of multiple hypothesis. J. Plankion Res. 9, 821-836.

Yen. J. 1987: Predation by Euchaeta norvegica Boeck on eggs and larvae of the North Atlantic cod Gadus morhua L. J. Exp. Mar. Biol. Ecol. 112. 283-296.

Yen. J. 1985: Selective predation by the carnivorous marine copepod Euchaeta elongata: Laboratory measurements of predation rates verificd by ficld observations of temporal/ spatial feeding patterns. Limnol. Oceanogr. 30, 577-595.

Yen, J. 1983: Effects of prey concentration, prey size, predator life stage. predator starvation and season on predation rates of the carnivorous marine copepod Euchaeta elongata. Mar. Biol. 75, 69-77.

Yen, J. 1982: Sources of variability in attack rates of Euchuetu elongata Esterly, a carnivorous marine copepod. J. exp. mar. Biol. Ecol. 63. 105-117. 